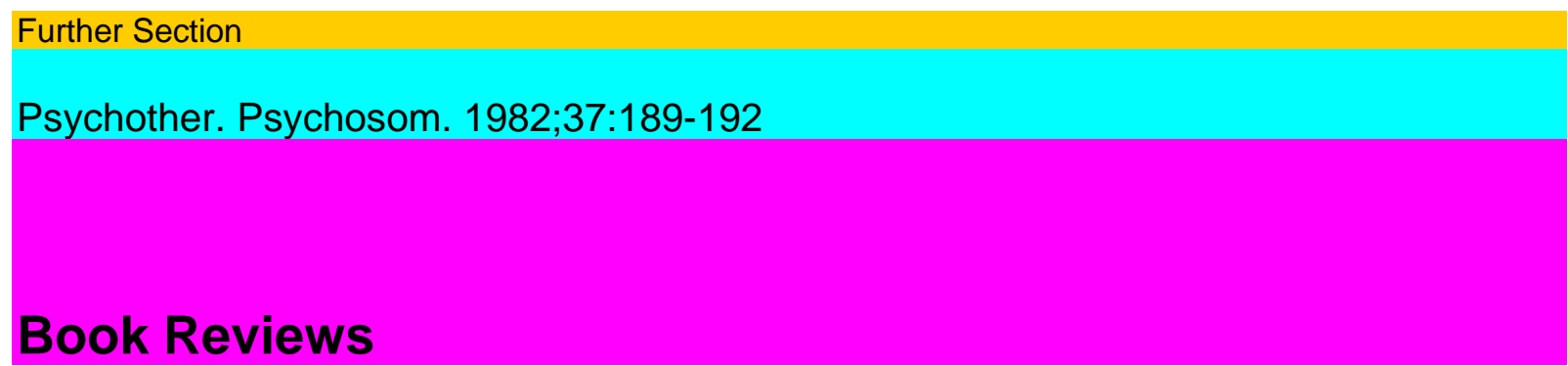

\title{
Roman Ferstl
}

Determinanten und Therapı des Essverhaltens

Springer, Berlin 1980

140 pp., 46 fig., 17 tab.; DM 36.-/US \$ 21.30

ISBN 3-540-09915-8

Dr. Roman Ferstl is co-worker of the Department of Psychology, Max-Planck-Insti-tute for Psychiatry, Munich.

The author is a well-known researcher in the field concerning the regulation of hunger and satiety including the inherent psychosomatic interactional processes. Following a general survey with regard to the central nervous and peripheral system as well as the psychological theories concerning satiety, Ferstl presents his experimental findings which include differences concerning the eating behavior of obese persons on the one hand and nonobese persons on the other hand. Finally, Ferstl informs us about his behavioral, therapeutically orientated results in obese patients which seem successful. Ferstl, starting from his impressive findings, discusses the possibility of predicting a psychotherapeutic success in these patients on the basis of certain behavioral parameters.

H. Freyberger, Hannover

William G. Niederland

Folgen der Verfolgung: Das Überlebenden-Syndrom, Seelenmord

Neue Folge Band 15

Suhrkamp, Frankfurt 1980. 244 pp.

ISBN 3-518-11015-2

Dr. William G. Niederland is the former president of the Psychoanalytic Association, New York and Clinical Professor Emeritus of psychiatry, State University of New York, Downstate Medical Center, Brooklyn, as well as acting as a practising psychiatrist and was previously consultant psychiatrist of the German consulate, New York, for many years.

Niederland represents a person who engaged himself intensively with great interest in former Nazi persecution victims. Therefore, on the basis of his great experience, he was able to set right a lot of mistaken decisions which were formely made by so-called 'Ver-trauens' doctors who were badly trained concerning the diagnosis of psychic damages in Holocaust people. Niederland regards his book as a 'Documents volume' which includes psychologicomedical records on the basis of Niederland's expert opinions ('Gutachten') with regard to the question of whether psychic damage existed in the examined former Nazi persecution victim.

S. Starting from his term 'Survivor syndrome'

Niederland greatly succeeds in clarifying both the psychopathology and psychodynamics concerning psychic damages as well as the 